\title{
Importance of Knowledge on Lipid Composition of Foods to Support Development towards Consumption of Higher Levels of n-3 Fatty Acids via Freshwater Fish
}

\author{
J. PICKOVA ${ }^{1,2}$ \\ ${ }^{1}$ Department of Food Science, Swedish University of Agricultural Sciences, Uppsala, Sweden, \\ ${ }^{2}$ VURH, University of South Bohemia in České Budějovice, Vodňany, Czech Republic
}

Received June 18, 2009

Accepted July 14, 2009

\begin{abstract}
Summary
The need of better labelling of fats in processed animal origin products is urgent. The lack of information makes it possible to exclude $n-3$ fatty acids in preparations of foods. The higher fat content, the higher $n-6 / n-3$ ratio seems to be a rule. It is desirable to broaden the labelling into which oils have been used when foods are processed. The dietary balance of $n-6$ and $n-3$ fatty acids is important for homeostasis and normal development in humans. The ratio between $n-6 / n-3$ fatty acids suggested to be evolutionary developed is between 1 and 4 . The main conclusion is that the fat sources used during processing and preparation of convenient foods have the largest impact on the food FA content and composition. A proposal is therefore that this should be declared on the product label especially the n-3 FA content. It is also of large importance to increase consumption of freshwater fish fed suitable feeds containing $n-3$ fatty acids in central Europe to enable a generally lower $n-6 / n-3$ ratio in the human diet. Therefore optimizing feeds to freshwater fish in culture is urgent and important.
\end{abstract}

\section{Key words}

$D H A \bullet E P A \bullet$ freshwater fish $\bullet n-6 / n-3$ ratio

\section{Corresponding author}

J. Pickova, Department of Food Science, Swedish University of Agricultural Sciences, PO Box 7051, 75007 Uppsala, Sweden. E-mail: Jana.Pickova@Imv.slu.se

\section{Background}

During the previous century and even more pronounced in the latest decades an increasing part of the Western diet is composed of fast and convenient foods
(Hagman et al. 1986, Baggio and Bragaguolo 2006), often rich in saturated fatty acids (SFA), monounsaturated fatty acids (MUFA) and polyunsaturated fatty acids (PUFA) of the n-6 series, (Taylor et al. 2000, Saguy and Dana 2003, Baggio and Bragaguolo 2006). In general, the total amount of PUFA in the Western diet has decreased, while at the same time, the ratio between n-6/n-3 PUFA has increased (Ailhaud et al. 2006, Anon, Dept of Health UK, 1994). This change is very obvious in children's diet and effects are visible. A Swedish study of 4 year old children showed on this trend, the intake of SFA was higher and total PUFA, especially the n-3 fatty acids (FA), lower than the general recommendations (Garemo et al. 2007).

We know that fish consumption is low and meat has become a relatively important source of long chain PUFA for many people (Kyle and Arterburn 1998, Scollan et al. 2001, Howe et al. 2006, De Henauw et al. 2007). As examples: in Sweden fish provides $5 \%$ of the total consumption of food and beverages at home, while meat contributes with $17 \%$ (www.scb.se), in Czech Republic the fish consumption per year is $1.5 \mathrm{~kg}$ compared to the average of total EU countries of $5 \mathrm{~kg}$ freshwater fish (www.zdrava-vyziva.net). In the Swedish study on 4 year old children $3 \%$ of the total fat intake came from fish while meat and egg contributed with $22 \%$ (Garemo et al. 2007).

Earlier studies on lipid composition of animal origin foods have shown that the FA composition of animal products is significantly influenced by a number of factors such as diet, species, breed, age and gender of the animals (Sargent et al. 1999, Zanardi et al. 2000, 
Scollan et al. 2001, Regost et al. 2004, Olsson and Pickova 2005, Estevez et al. 2006). Diet is most likely the dominating factor in most cases. The say "You are what you eat" is a real truth when it comes to fat composition of animal tissues. In addition, the quality of oils and fats during processing of the foods has a strong influence on the FA composition of servings (Ansorena and Astiasaran 2004). Analysis of FA composition of some different brands of common fish and meat fast foods (Sampels et al. 2009) was performed and compared to the original raw product. In order to illustrate the variation in fat composition, the obtained data were compared to the data available in the official food database of the same country (National Food Administration 2008). In that study was found that the highest variation in fat composition of the food products was due to processing (Sampels et al. 2009). The investigated fish products were based on lean fish species, and the FA composition of the products was markedly altered by the fat source used in the different processes to fast food products. There was no information on the packages about the fat used for production, except that it was a vegetable oil. It was assumed that use of different oils in the different brands caused these differences. Some products were most probably based on corn oil, while some others probably used palm oil. The fat content and the values of 16:0 and 18:1n-9 were increased in those products compared to the frozen fish. The addition of oil to get a desirable crumb increased the fat content and changed the total FA profile, markedly increasing the $n-6 / n-3$ ratio and fat content (Fig. 1) (Sampels et al. 2009). The producers are not obliged to list the used fat on the ingredient list, which is quite unfortunate, as it had a large influence on the fat composition. These values might further change when the products are fried by the consumers (Saguy and Dana 2003, Ramirez et al. 2005), a factor which may further increase the $\mathrm{n}-6 / \mathrm{n}-3$ ratio (Soriguer et al. 2003).

In ruminant origin animal products grass and green feed lead to higher proportions of n-3 PUFA compared to concentrates that are often produced with cereals and oils rich in 18:2n-6 (Wood et al. 2003). Also residue cakes and meals from rapeseed, hempseed and linseed oil production can have the same impact on all animal products. Therefore lard can be expected to have a very variable composition depending on the feed of the pigs. This is suspected to lead to variation of FA composition in these types of products that should be studied more extended.

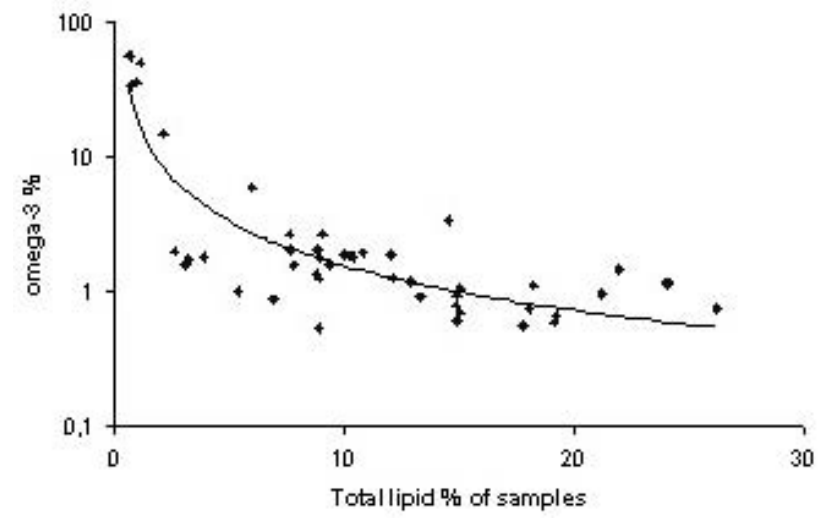

Fig. 1. Correlation between the lipid content $(\% w / w)$ and omega-3 fatty acids (\% of total lipid, log scale) in products which were analyzed and data from the Swedish food database. Adapted from Samples et al. 2009.

The results from the analyzed foods in Sampels et al. (2009) suggest that in general a higher fat content in the products leads to a lower proportion of n-3 (Fig. 1). The highest content of $n-3$ was found in the unprocessed fish. If the unprocessed fish was excluded in the analysis, there was no significant correlation between fat content and n-3 FA.

Five-10 \% of the energy intake per day is recommended as PUFA, including about $1 \% \mathrm{n}-3$ PUFA, according to the nutritional recommendations in many countries. The balance between LA and ALA (acids linoleic and linolenic, is important for further transformation by desaturation and elongation to the LCPUFA, and a high intake of n-6 FA will lead to a decrease of $\mathrm{n}-3$ long chain PUFA (LCPUFA). Depending on the ratio of $n-6 / n-3$ in the diet, the conversion of ALA to longer chain n-3 PUFA can vary (Cunnane et al. 2003). It is expected, the total proportion of PUFA is much lower in the meat products than in the fish products. Despite the high n-6/n-3 ratio and the decreased amount of 22:6n-3 in the fish products, they still contained ten times more of LCPUFA than the meat products. Since meat dominates the food intake, the lower ratio $n-6 / n-3$ FA in alternative (such as organic and ecological, fed mostly green feeds) production raised animals might be important.

It would be desirable also to include information about the livestock diet and information about animal products produced in alternative production systems in databases, as for example beef and mutton from grazing animals or other food products, but it is even more desirable that the added fat or vegetable oil is declared to origin. Such knowledge can enable an interdisciplinary 
dialogue from feed producers and animal farmers, to food industry and medical and nutritional professionals, in order to optimize fat composition and the development of convenient foods to be nutritionally favorable.

To address more real numbers when nutrition studies on fat intake and composition are performed, more data are needed. For the calculation of data in studies including food frequency questionnaires, 24-hour recall and 3-7 days of dietary recording, as exemplified in references (Matthys et al. 2006, Garemo et al. 2007, Sioen et al. 2007), the food items are not analysed but available food databases are used (Nevo 1993, Nubel 1995, National Food Administration 2008). These databases usually do not present different brands or refer to different feeding strategies and processing methods. There is presently no obligation for producers to declare which types of fat were added during processing.

\section{Fish farming and the beneficial effects of fish consumption}

The new strategy to increase fish availability especially within EU, gives a strong demand of fish feeds. These are often composed with fish as the main part of the raw products used in the different brands. Fish oils generally are processed mainly from marine pelagic fatty fish species. The main intake of n-3 long chain PUFA within EU is based on the production of salmonids in Northern part of Europe, Norway and Scotland as the main producers, and sea bass and sea bream in the Mediterranean area. The traditional fish feeds for these species contained a large proportion of fish as ingredients. Today, the situation is changing; fish ingredients are both expensive and getting scarce (Pickova 2009). Therefore, it is time now to develop culture of these and other species not that much dependent on fish ingredients, being suppliers of fish fatty acids, in fact via the conversion of shorter n-3 fatty acids from plant oils in fish feeds. Freshwater fish are at the moment an underestimated resource and the feeding strategies to carps, catfish and other freshwater species in culture have to be developed to optimize the PUFA content of these fish species. The fatty acids eicosapentaenoic acid (EPA, 20:5 $\Delta 5,8,11,14,17$ ) and docosahexaenoic acid (DHA, 22:6 $\Delta 4,7,10,13,16,19)$ are important components of fish. Fish oil PUFAs are sometimes also called highly unsaturated fatty acids (HUFA), where highly means at least three double bonds.

The demand for fish continues to climb but annual harvests of fish have remained roughly stable since the mid-1980s, whereas aquaculture has been growing with a rate of around 8-9 \% per anno during this period (FAO statistics 2006). The expansion of aquaculture continues in almost all world regions. Aquaculture is crucial to meet the increasing demand for fish and also to support the attempts to maintain wild fish populations (Fig. 2). Therefore the challenge is to increase the culture of species suitable in relation to the feeds available without compromising the fish nutritional quality for consumption, especially with optimized levels of PUFA. Here the freshwater fish culture is of crucial importance, generally having a relatively high capacity to transform linolenic acid (ALA) to the longer and more desaturated products such as EPA and DHA.

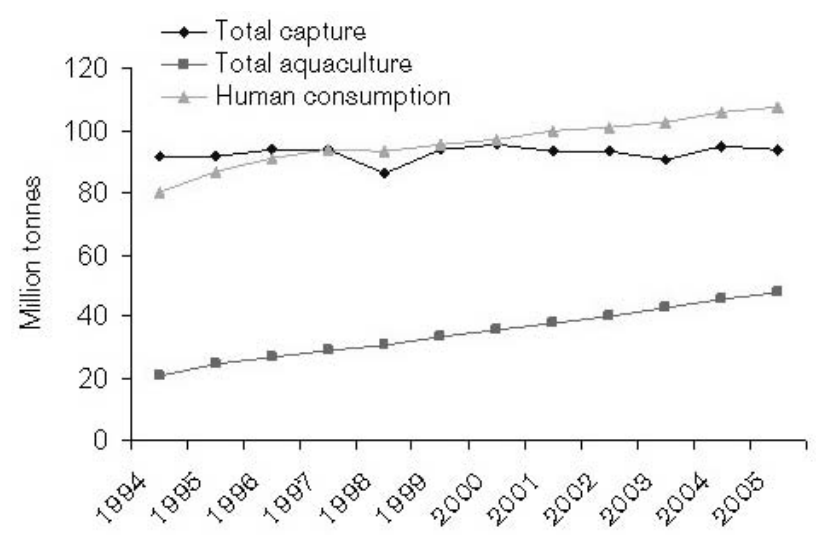

Fig. 2. Total capture, total aquaculture production and human consumption of fish from year 1994 to 2005 , data are taken from SOFIA 2002, 2004, 2006.

\section{Ongoing trial}

In ongoing trials (Mráz and Pickova 2009 and unpublished), carp has been fed different supplements in addition to the plankton available in ponds. Ongrowing fish had access to plankton or plankton with addition of cereals or pellets containing rapeseed cake. The fish without any supplementation were characterized by high content of n-3 PUFA, especially EPA and DHA. The fish supplemented with rapeseed pellets had modest level of n-3 PUFA and the fish supplemented with cereals were characterized by high content of oleic acid and low levels of n-3 FA. This tissue and in particular the storage fraction have less favorable, with regard to human nutrition, ratio polyunsaturated n-6/n-3 fatty acids than total phospholipids, which can be improved by a change in feed composition by other vegetable additives than cereals. We conclude that common carp has a potential to 
become an attractive fish in terms of lipid content and composition. The nutritive value of the lipids in the present carp production is high, especially in the lean parts of the fillets, in relation to the amount of n-3 PUFA in the total diet of central Europe. In addition, several possibilities to improve the lipid composition of cultured carp in the traditional pond production are discussed and under evaluation (Mráz and Pickova 2009).

\section{Discussion}

The incorporation of fish fatty acids as healthy additives in foods and as formulations in different forms of health promoting capsules or oils is currently increasing. This makes fish oils extremely valuable and explains the continuous increase in their prices.

In general, the health effects of fish oils are ascribed especially to EPA and DHA. These fatty acids have a number of beneficial properties in human health. A meta-analysis by Mozaffarian and Rimm (2006) demonstrated the advantage of an intake of these fatty acids in relation to cardio vascular disorders and neurodevelopment during gestation and infancy. The major conclusion from their study was that benefits of fish intake exceed the potential risks of possible harmful effect of pollutants (Mozaffarian and Rimm 2006). The amount of DHA recommended for daily intake varies between studies (Mozaffarian and Rimm 2006). Recommendation on intake of DHA and EPA are given in several countries, e. g. from 1994 in United Kingdom (Anon 1994) as well as in United States (Simopoulos et al. 2000). The need for DHA and EPA is caused by the fact that the ability of mammals to elongate and desaturate 18 carbon fatty acid chains, both n-6 and n-3, is limited. The n-3 polyunsaturated fatty acids are important for cell membrane fluidity, regulation of cell signaling (Calder 2008). Dietary intake of n-3 fatty acids is known to influence the expression of several genes, such as PPARs and SRBPI (Price et al. 2000). An n-6/n-3 ratio $1: 1-4: 1$ is suggested by many studies to be the evolutionary developed optimum in the human diet (Simopoulos 2000). Fish having such a low and lower ratio are important as a beneficial part of the human diet, whereas vegetable oils generally have higher ratio of n-6/n-3. Plant oils which contain n-3 fatty acids in significant amount are linseed (flaxseed), rapeseed (canola) and hempseed (Table 1) but also these oils almost lack the important long chain n-3 PUFA. The n-6 and n-3 fatty acids are metabolically and functionally distinct and have many opposing physiological effects. The dietary balance of n-6 and n-3 fatty acids is important for homeostasis and normal development in humans (Simopoulos 2002). Recently, EPA and DHA have been suggested to increase the production of the anti-inflammatory bioactive lipid modulators resolvins (Massaro et al. 2008). Today, the importance of DHA as a nutrient important in gene expression and thereby a factor in lipid metabolism is recognised.

Table 1. Approximate proportions (\% of total identified fatty acids) of the main polyunsaturated fatty acids linoleic, $18: 2 n-6$, and linolenic, 18:3n-3, in the three plant oils. Values are from own analytical data (unpublished).

\section{Fatty acid \% $\quad 18: 2 n-6 \quad 18: 3 n-3 \quad$ Ratio n-6/n-3}

\begin{tabular}{llll}
\hline Rapeseed & 20 & 10 & 2.0 \\
Hempseed & 53 & 20 & 2.5 \\
Linseed & 15 & 55 & 0.3 \\
\hline
\end{tabular}

Health claims can relate to contents of nutritionally beneficial compounds or disease risk reduction claims. Omega-3 health claims can be divided in two different claims; omega-3 polyunsaturated fatty acids (ALA rich PUFA oils) and long chain omega-3 polyunsaturated fatty acid containing oils (LC omega-3 rich PUFA oils, eg. fish oils), the latter containing mostly EPA and DHA. The legislation related to the oil omega-3 fatty acid content and composition is still under revision and will likely continue to undergo changes as new research studies are published and scrutinized

Seafood (the common name for fish and crustaceans also from freshwater) is the richest and most efficient source of dietary very long chain n-3 fatty acids. World freshwater and marine aquaculture will constitute more than half of the world seafood (fish and others produced both in freshwater and in marine environment) production within only a few years time (FAO, 2007). Therefore aquaculture is the world's fastest growing food production sector, bringing great potential for food supply, and for enhanced trade and economic benefits. Use of high-energy feeds has been of major importance for the development of cost effective fish farming and fast growing fish. Fishmeal and fish oil are limited resources and the importance of plant seeds, rich in protein and fat, in fish feeds is increasing. Grains and other plant products are cost efficient in aquaculture feeds and are considered more sustainable than fish meal and 
fish oil. Grains and other seeds often contain compounds that affect nutrient uptake and utilization and possibly fish health, positively or negatively, by their potential modulating effects on the immune system, as well as interaction with the fat metabolism. In addition, microbial sources (algae, fungi and bacteria) are upcoming alternatives to be included in aquaculture feeds. Such sources add to the human food bank rather than only transforming one human food source to another. Different alternative sources of oils and proteins are being tested with good results, except for the amounts of EPA and DHA in the fish (reviewed in Pickova and Mørkøre 2007). It was recently shown that addition of sesame lignans to different vegetable oils increased the percentages of DHA in white muscle of rainbow trout by approximately $30-40 \%$ by increasing the desaturation index of $n-3$ fatty acids (22:6/18:3). It was concluded that supplementation of fish feed with n-3 fatty acids (e.g. from rapeseed oil, linseed oil or mixed oils) and sesame lignans increases the proportions of highly unsaturated n-
3 fatty acids, especially DHA. It so affects the expression of a few nuclear receptors (Trattner et al. 2008). Recent developments in the field of nutrigenomics and metabonomics are foreseen to promote our understanding of gene-nutrient interactions. Of special importance is the effect of n-3 fatty acids including ALA, EPA and DHA and lipid-soluble synergists on nuclear receptors including peroxisome proliferators activated receptors (PPARs), retinoid $\mathrm{X}$ receptors (RXR) and sterol regulatory element binding proteins (SREBPs) (Trattner et al. 2008).

\section{Conflict of Interest}

There is no conflict of interest.

\section{Acknowledgements}

This project was supported by grant No QH 92307 of Ministery of Agriculture, Czech Republic and Swedish University of Agricultural Sciences.

\section{References}

AILHAUD G, MASSIERA F, WEILL P, LEGRAND P, ALESSANDRI J-M, GUESNET P: Temporal changes in dietary fats: Role of n-6 polyunsaturated fatty acids in excessive adipose tissue development and relationship to obesity. Prog Lipid Res 45: 203-236, 2006.

Anon. Department of Health UK. Nutritional aspects of cardiovascular disease. Report on Health and Social Subjects London, Her Majesty's stationary office No. 46. 1994.

ANSORENA D, ASTIASARAN I: The use of linseed oil improves nutritional quality of the lipid fraction of dryfermented sausages. Food Chem 8: 69-74, 2004.

BAGGIO SR, BRAGAGNOLO N: The effect of heat treatment on the cholesterol oxides, cholesterol, total lipid and fatty acid contents of processed meat products. Food Chem 95: 611-619, 2006.

CALDER PC: Polyunsaturated fatty acids, inflammatory processes and inflammatory bowel diseases. Mol Nutr Food Res 52: 885-897, 2008.

CUNNANE SC, RYAN MA, NADEAU CR, BAZINET RP, MUSA-VELOSO K, MCCLOY U: Why is carbon from some polyunsaturates extensively recycled into lipid synthesis? Lipids 38: 477-484, 2003.

DE HENAUW S, VAN CAMP J, STURTEWAGEN G, MATTHYS C, BILAU M, WARNANTS N, RAES K, VAN OECKEL M, DE SMET S: Simulated changes in fatty acid intake in humans through n-3 fatty acid enrichment of foods from animal origin. J Sci Food Agric 87: 200-211, 2007.

ESTEVEZ M, MORCUENDE D, CAVA R: Extensively reared Iberian pigs versus intensively reared white pigs for the manufacture of frankfurters. Meat Sci 72: 356-364, 2006.

FAO statistics, www.FAO.org

GAREMO M, ARVIDSSON LENNER R, STRANDVIK B: Swedish preschool children eat to much junk food and sucrose. Acta Paediatr 96: 266-272, 2007.

HOWE P, MEYER B, RECORD S, BAGHURST K: Dietary intake of long-chain [omega]-3 polyunsaturated fatty acids: contribution of meat sources. Nutrition 22: 47-53, 2006.

KYLE DJ, ARTERBURN LM: Single cell oil sources of docosahexaenoic acid: clinical studies. The Return of n-3 Fatty Acids into the Food Supply 1. Land-based Animal Food Products and Their Health Effects, A. P. SIMOPOULOS, (ed) Basel: Karger. 83: 117-131, 1998. 
MASSARO M, SCODITTI E, CARLUCCIO MA, DE CATERINA R: Basic mechanisms behind the effects of n-3 fatty acids on cardiovascular disease. Prostagl Leukot Essent Fatty Acids 79: 109-115, 2008.

MATTHYS C, DE HENAUW S, BELLEMANS M, DE MAEYER M, BACKER G: Sources of saturated fatty acids in Belgian adolescents' diet: implications for the development of food-based dietary guidelines. Br J Nutr 95: 546-554, 2006.

MOZAFFARIAN D, RIMM EB: Fish intake, contaminants, and human health - Evaluating the risks and the benefits. JAMA 296: 1885-1899, 2006.

MRAZ J, PICKOVA J: Differences between lipid content and composition of different parts of fillets from crossbred farmed carp (Cyprinus carpio). Fish Physiol Biochem DOI :10.1007/s10695-008-9291-5: pp 1-9, 2009.

National Food Administration Livsmedelstabeller/Specialtabeller, fatty acids, http://www.slv.se/upload/dokument/ mat/ldb/Fettsyror.xls, National Food Administration, Uppsala, Sweden Excel table. (In Swedish) 2008.

Nevo NEVO table, Nederlands voedingsmiddeltabel (Dutch Food composition table), Zeist, The Netherlands 95. (In Flemish) 1993.

Nubel Nubel Belgische Voedingsmiddeltabel, tweede uitgave (Belgian Food Composition Table, 2nd edition) Ministerie van Voklsgezondheid, Brussels Belgium 11. (In Flemish). 1995.

OLSSON V, PICKOVA J: The influence of production systems on meat quality, with emphasis on pork. Ambio 34: 338-343, 2005.

PICKOVA J, MØRKØRE T: Alternate oils in fish feeds. Eur J Lipid Sci Technol 109: 256-263, 2007.

PICKOVA J: Chapter 20, Fish lipids. In: Gourmet and Health-Promoting Oils. A. KAMAL-ELDIN, R. A. MOREAU (eds). AOCS Press, Urbana, Illinois, 2009, pp 515-526.

PRICE PT, NELSON CM, CLARKE SD: Omega-3 polyunsaturated fatty acid regulation of gene expression. Curr Opin Lipidol 11: 3-7, 2000.

RAMIREZ M, MORCUENDE D, ESTEVEZ M, CAVA LOPEZ R: Fatty acid profiles of intramuscular fat from pork loin chops fried in different culinary fats following refrigerated storage. Food Chem 92: 159-167, 2005.

REGOST C, JAKOBSEN JV, RORA AMB: Flesh quality of raw and smoked fillets of Atlantic salmon as influenced by dietary oil sources and frozen storage. Food Res Int 37: 259-271, 2004.

SARGENT J, BELL G, MCEVOY L, TOCHER D, ESTEVEZ A: Recent developments in the essential fatty acid nutrition of fish. Aquacult 177: 191-199, 1999.

SAGUY IS, DANA D: Integrated approach to deep fat frying: engineering, nutrition, health and consumer aspects. $J$ Food Eng 56: 143-152, 2003.

SAMPELS S, STRANDVIK B, PICKOVA J: Processed animal products with emphasis on polyunsaturated fatty acid content. Eur J Lipid Sci Technol 111: 481-488, 2009.

SCOLLAN ND, CHOI N-J, KURT E, FISHER AV, ENSER M, WOOD JD: Manipulating the fatty acid composition of muscle and adipose tissue in beef cattle. Br J Nut 85: 115-124, 2001.

S. C. Statistics Sweden: Privat konsumtion av olika livsmedel och drycker 2001, http://www.scb.se/templates/ tableOrChart_37527.asp, 2001.

SIMOPOULOS AP: Human requirement for n-3 polyunsaturated fatty acids. Poultry Sci 79: 961-970, 2000.

SIMOPOULOS AP: The importance of the ratio of omega-6/omega-3 essential fatty acids. Biomed Pharmacother 56: 353-379, 2002.

SIOEN I, MATTHYS C, DE BACKER G, VAN CAMP J, DE HENAUW S: Importance of seafood as nutrient source in the diet of Belgian adolescents. J Hum Nutr Diet 20: 580-589, 2007.

SORIGUER F, ROJO-MARTINEZ G, DOBARGANES MC, ALMEIDA JMG, ESTEVA I, BELTRAN M, DE ADANA MSR, TINAHONES F, GOMEZ-ZUMAQUERO JM, GARCIA-FUENTES E, GONZALEZROMERO S: Hypertension is related to the degradation of dietary frying oils. Am J Clin Nutr 78: 1092-1097, 2003.

TAYLOR DS, FISHELL VK, DERSTINE JL, HARGROVE RL, PATTERSON NR, MORIARTY KW, BATTISTA BA, RATCLIFFE HE, BINKOSKI AE, KRIS-ETHERTON PM: Street foods in America - a true melting pot, Street Foods, A. P. SIMOPOULOS (ed), Basel, Karger 6: 25-44, 2000. 
TRATTNER S, RUYTER B, ØSTBYE TK, GJØE T, ZLABEK V, KAMAL-ELDIN A, PICKOVA J: Sesamin increases alpha-linolenic acid conversion to docosahexaenoic acid in Atlantic salmon (Salmo salar L.) hepatocytes: Role of altered gene expression Lipids 43: 997-1008, 2008.

WOOD J D, RICHARDSON RI, NUTE GR, FISHER AV, CAMPO MM, KASAPIDOU E, SHEARD PR, ENSER M: Effects of fatty acids on meat quality: a review. Meat Sci 66: 21-32, 2003.

www.SOFIA (2002). The state of world fisheries and aquaculture [online]. Available from: http://www.fao.org/ docrep/005/y7300e/y7300e00.htm [Accessed 2009-02-10].

www.SOFIA (2004). The state of world fisheries and aquaculture [online]. Available from: http://www.fao.org/ docrep/007/y5600e/y5600e00.htm [Accessed 2009-02-10].

Www.SOFIA (2006). The state of world fisheries and aquaculture [online]. Available from: http://www.fao.org/ docrep/009/A0699e/A0699e00.htm [Accessed 2009-02-10].

ZANARDI E, NOVELLI E, GHIRETTI GP, CHIZZOLINI R: Oxidative stability of lipids and cholesterol in salami Milano, coppa and Parma ham: dietary supplementation with vitamin E and oleic acid. Meat Sci 55: 169-175, 2000 .

Zdrava vyziva, http://www.zdrava-vyziva.net/sladkovodni-ryby.php, approached 2009-06-10. 